\title{
Role of meteorology and local orography on a flood event in the Lower Subansiri Basin and post-flood changes to land use and land cover
}

\author{
Partha Pratim Gogoi ${ }^{1}$, V. Vinoj ${ }^{1, *}$ and Parag Phukon ${ }^{2}$ \\ ${ }^{1}$ School of Earth, Ocean and Climate Sciences, Indian Institute of Technology Bhubaneswar, Arugul, Jatni 752 050, India \\ ${ }^{2}$ Department of Geological Sciences, Gauhati University, Jalukbari 781 014, India
}

\begin{abstract}
Extreme rainfall in the Arunachal Himalaya has the potential to create floods in the downstream regions of Assam, with the rivers in the region exceeding their capacity and competence. High-intensity rainfall also leads to higher sediment generation in the subHimalayan catchment. Though floods have been incurring huge losses to both life and property frequently in Assam, there are only a few studies on the meteorological and orographic dynamics of such extreme rainfall events and their potential to create a flood. The present study highlights the pre-flood and post-flood scenario in the Lower Subansiri Basin (LSB) in Brahmaputra valley, Assam, through satellite data analysis and ground field surveys to establish linkages between extreme rainfall events and a subsequent major flood event that occurred during September 2012. We observed that the flood was mostly triggered by the extreme rainfall induced by orographic lifting of moisture-laden winds from the south. In addition to submerging an area of $\sim 1900 \mathrm{~km}^{2}$, the flood also brought along fragile Neogene clastics that increased barren soil over the floodplains by $\sim 47 \%$ compared to the pre-flood period, thus disrupting the agrarian economy of the region for several cropping seasons. These findings demonstrate the need for a reliable meteorological forecast for extreme rainfall as a prerequisite for developing effective flood-forecasting models in the Brahmaputra valley, which will positively contribute towards flood hazard management in the region.
\end{abstract}

Keywords: Extreme rainfall, flood, meteorology, orography, sand aggradation.

ON a global basis, deaths caused by floods are the highest $(\sim 26 \%)$ followed by those due to tropical cyclones $(\sim 19 \%)^{1,2}$. The causative factors for such devastating floods need to be understood to prioritize planned mitigation strategies. The Lower Subansiri Basin (LSB), a subcatchment of the Brahmaputra basin in the frontal areas of the Arunachal Himalaya, is vulnerable to disastrous floods that have led to loss of life and property. With a

*For correspondence. (e-mail: vinoj@iitbbs.ac.in) population of $\sim 1.5$ million (ref. 3 ), the high vulnerability of LSB to natural disaster is a risk to the socio-economic balance of the region ${ }^{4}$.

Most of the tributaries of the Brahmaputra are rainfed and there is a direct linkage between rainfall intensity and floods in the North Eastern Region (NER) of India. Highintensity rainfall is also linked to higher sediment generation due to erosion in the upper catchment, particularly in the Arunachal Himalaya. Very high sediment flux into the rivers originating in Arunachal Himalaya triggers cascading effects downstream of the mountain exits in north Brahmaputra plain namely, floodplain and riverbed aggradation, large scale channel changes, bank erosion and flooding. In addition, increasing trend of both frequency and magnitude of extreme rainfall events has been observed over Central and North East (NE) India ${ }^{5,6}$, which will have implications for high-intensity hydrological events. Also, many studies using satellite and field observations, have highlighted the vulnerability of flood and sand aggradation in Assam ${ }^{4,7-14}$. However, the link between meteorological dynamics and post-flood impact on land cover is rarely addressed and necessitates urgent analysis. This study is an attempt in that direction in LSB. We have chosen a part of the LSB in Assam which was heavily affected by major floods in 2012 during June-July-August-September (JJAS) (Figure $1 a$ ). It may be mentioned that as much as $\sim 4.65$ lakh hectare area had been submerged by the July 2012 flood event affecting $\sim 2.3$ million people and 3829 villages $^{14}$. We will discuss some of the meteorological factors that may have contributed to intensifying the heavy rainfall leading to floods in the LSB and the subsequent changes to land cover.

\section{Data and methodology}

The daily Tropical Rainfall Measuring Mission (TRMM) rainfall datasets (TRMM_3B42_Daily_v7) were used to evaluate the changing rainfall characteristics over LSB. First, we show the spatial climatology of annual rainfall over NE India (Figure $1 a$ ). In Figure $1 a$, LSB is identified as the small red polygon within Box 1. Rainfall over the whole catchment area encompassing LSB influences 

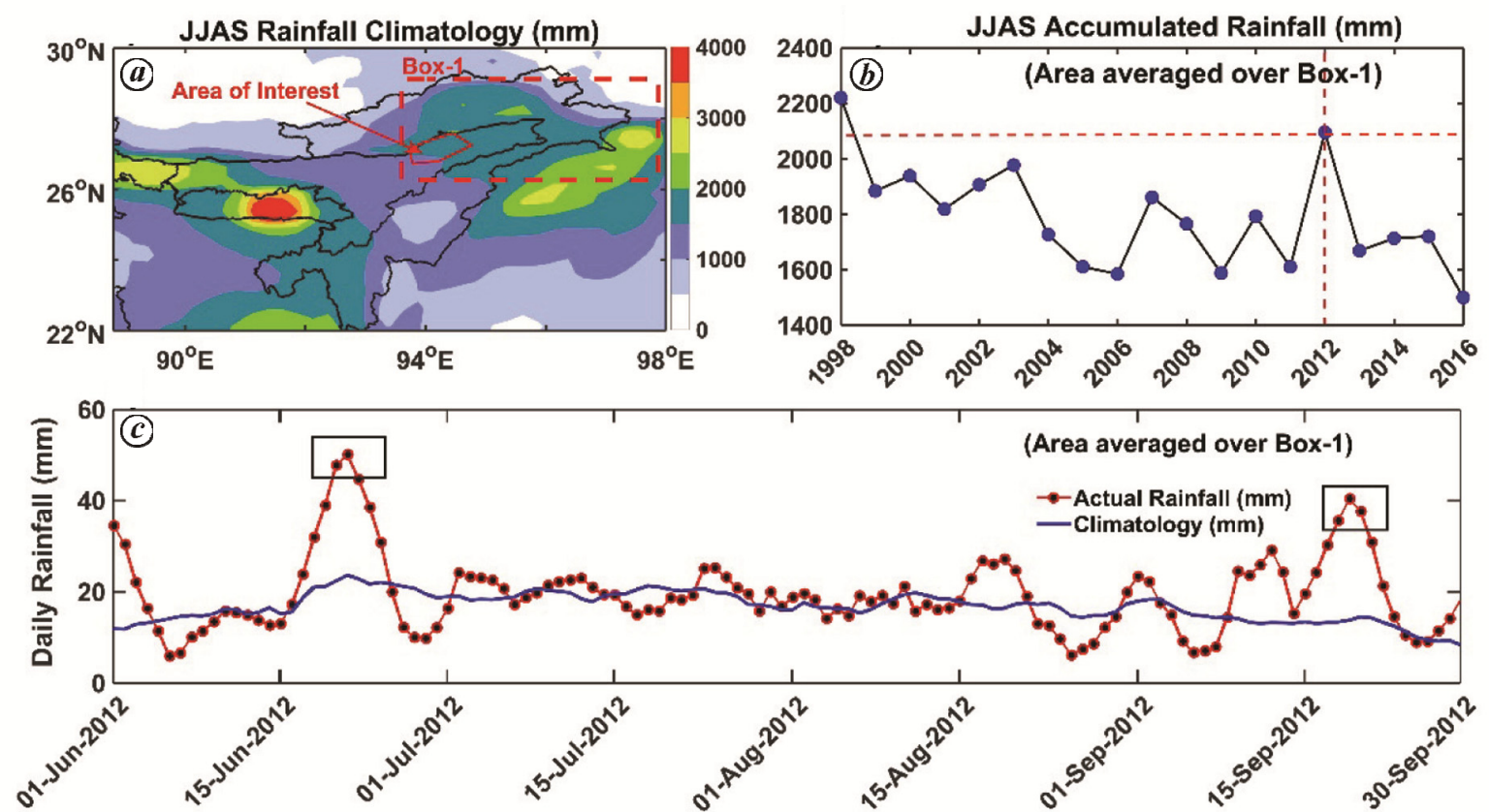

Figure 1. $\boldsymbol{a}$, The 15-yr climatological rainfall (mm) using TRMM dataset (1998-2012) over North East India. Box 1 shows the region of highest rainfall which contributes immensely to river discharge in the downstream regions of Assam. The study area, Lower Subansiri Basin (LSB) is shown inside Box 1 as the area of interest. $\boldsymbol{b}$, Annual accumulated rainfall (mm) over Box 1. $\boldsymbol{c}$, Daily rainfall over Box 1 during JJAS of 2012 . Source: TRMM $0.25^{\circ} \times 0.25^{\circ}$ Satellite Product.

Table 1. Details of datasets used in this study

\begin{tabular}{lcc}
\hline Dataset & Spatial resolution & Source \\
\hline $\begin{array}{l}\text { Level-1 surface reflectance } \\
\quad \text { for LULC analysis) }\end{array}$ & $30 \mathrm{~m} \times 30 \mathrm{~m}$ & LANDSAT 4/5, 7 \\
Rainfall & $0.25^{\circ} \times 0.25^{\circ}$ & TRMM \\
Wind speed $(u, v$ and $w$ & $0.25^{\circ} \times 0.25^{\circ}$ & ERA5 \\
$\quad$ components) & In situ & - \\
Field observations & $1 \mathrm{~km} \times 1 \mathrm{~km}$ & NGDC, NOAA \\
Topography & &
\end{tabular}

run-off in this basin, though the amount of rain over the basin itself is not the highest with respect to the whole NER of India. Figure $1 b$ shows the yearly accumulated rainfall during monsoon season (June-September) over LSB since 1998. Though there is a slight decrease in the overall rainfall over the region, it is found that 2012 witnessed one of the highest rains in recent times. We have therefore chosen this year and the ensuing floods for our analysis. Figure $1 c$ shows the daily rainfall during JJAS 2012. There were two episodes of heavy/extreme rainfall during the period with one starting on 15 June and another on 15 September 2012. The rainfall continued to increase for about 6 days before peaking on 21 June and 19 September 2012 respectively. The first event occurred in June, which is climatologically the early monsoon season. The second event occurred in September during the retreating phase of the monsoon. Satellite imageries with clear-sky scenes are difficult to obtain during the early/ peak monsoon owing to cloud cover and rainfall. There- fore, considering the availability of both LANDSAT and other available supplementary datasets required for our analysis, we chose to analyse the second peak in extreme rainfall that occurred during the period 19 to 21 September 2012. This rainfall event was also exceptional as during this period the Indian Summer Monsoon (ISM) starts retreating, resulting in a decrease in rainfall intensity. Thus, this extreme rainfall event provided an excellent case for undertaking a study linking meteorological conditions to rainfall that further led to floods downstream and altered the land type, thereby affecting agrarian activities in the floodplains.

\section{Land-use classification}

In order to quantify the changes in land use and land cover (LULC) before and after the flood, we have used NASA's LANDSAT Level-1 satellite reflectance. Four categories, namely water, dense forest (DF), light vegetation/agriculture (LV/Agri) and barren/sand/uncultivated were classified/identified in the LSB from LANDSAT reflectance using maximum likelihood classifier (MLC) supervized algorithm and post-flood changes were analysed for these land types. The classification was then authenticated with detailed field photographs and multiple field surveys of the flood hazard zones carried out during October 2012 by a team of researchers from Gauhati University. Table 1 provides details of the all datasets used in this work. The meteorological analyses were carried out using the different components of winds 

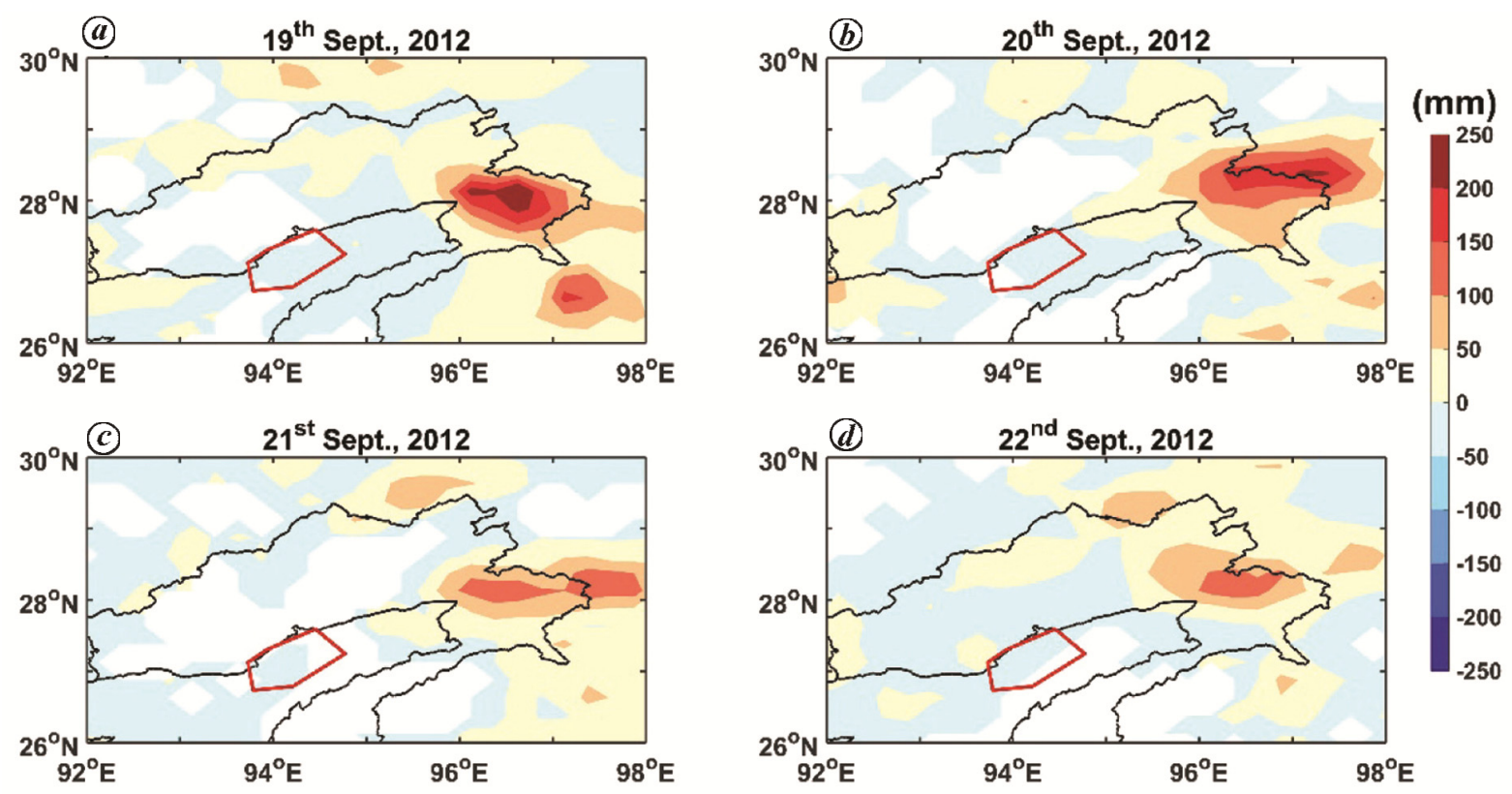

Figure 2. Rainfall anomaly with respect to the 15-yr daily climatological mean covering LSB and Arunachal Pradesh on (a) 19 , (b) 20 ,

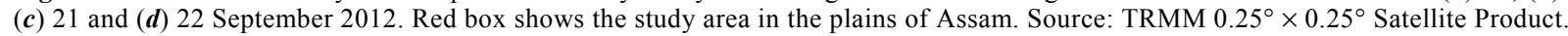

extracted from the European Centre for Medium-Range Weather Forecasts' (ECMWF) ERA5 products, which have high accuracy and fidelity. In addition, we have also used the elevation/topography model data from the National Geophysical Data Center (NGDC), NOAA, USA, available at a resolution of $1 \mathrm{~km}$ to characterize the orography of the region and its influence on regional rainfall $^{15}$.

\section{Results and discussion}

\section{Rainfall analysis}

Figure $1 c$ shows that rainfall over Box 1 is higher than the climatological mean (1998-2012) during 19 to 22 September 2012. Figure 2 shows the daily rainfall anomaly or departure from the 15-yr climatological mean (19982012) during 19 to 22 September 2012. It was observed that rainfall during the same period over the Lower Himalayan Region in the eastern part of Arunachal Pradesh exceeded $250 \mathrm{~mm}$ on 19 September (Figure 2). Thus, the rainfall was extreme according to the definition of India Meteorological Department (IMD; >244.5 mm; http:// imd.gov.in/section/nhac/termglossary.pdf). It may be mentioned that the region with highest rainfall is also one where several tributaries of the Brahmaputra converge. Therefore, increased rainfall during any time over this region is expected to cause floods if it exceeds the carrying capacity of the river. The rainfall amount that peaked during 19 September gradually decreased in a few days (Figure $2 a-d$ ). It is known that rainfall in the Lesser
Himalaya plays a significant role in determining the river discharge and thereby the flood downstream. Therefore, rainfall quantification and prediction is a prerequisite for skillful mitigation measures.

The NER of India is expected to experience significant orographic rainfall due to its undulating topography. We have therefore explored the convergence of winds, their direction and hence the resultant rainfall over this region.

\section{Convergence and horizontal wind direction}

Rainfall during ISM is mostly influenced by the crossequatorial flow ${ }^{16}$ and hence there is moisture convergence over the Indian region. Studies have suggested that NE India is also influenced by extra-tropical cyclones from the northwest bringing rainfall to this region ${ }^{17}$. We analysed the spatial pattern of winds at $850 \mathrm{hPa}$ over the region with highest rainfall (Figure 3 ). It was found that most of the winds blow from the southwesterly direction, thereby negating the possibility of any influence from the extra-tropics. It may also be noted that only a portion of Figure 3 shows the wind vectors corresponding to $850 \mathrm{hPa}$ level. This is due to the complex topography of the region that often exceeds $850 \mathrm{hPa}$ pressure level to the north. It is also clear that the region is encompassed by high mountains to the north, east and southeast, thereby forming a closed topographic structure capable of blocking any winds from the southwest which forms the only channel for any meteorological disturbance to enter the mountain range. It is clear from Figure 3 that the winds converge over the northeastern edge of the closed 

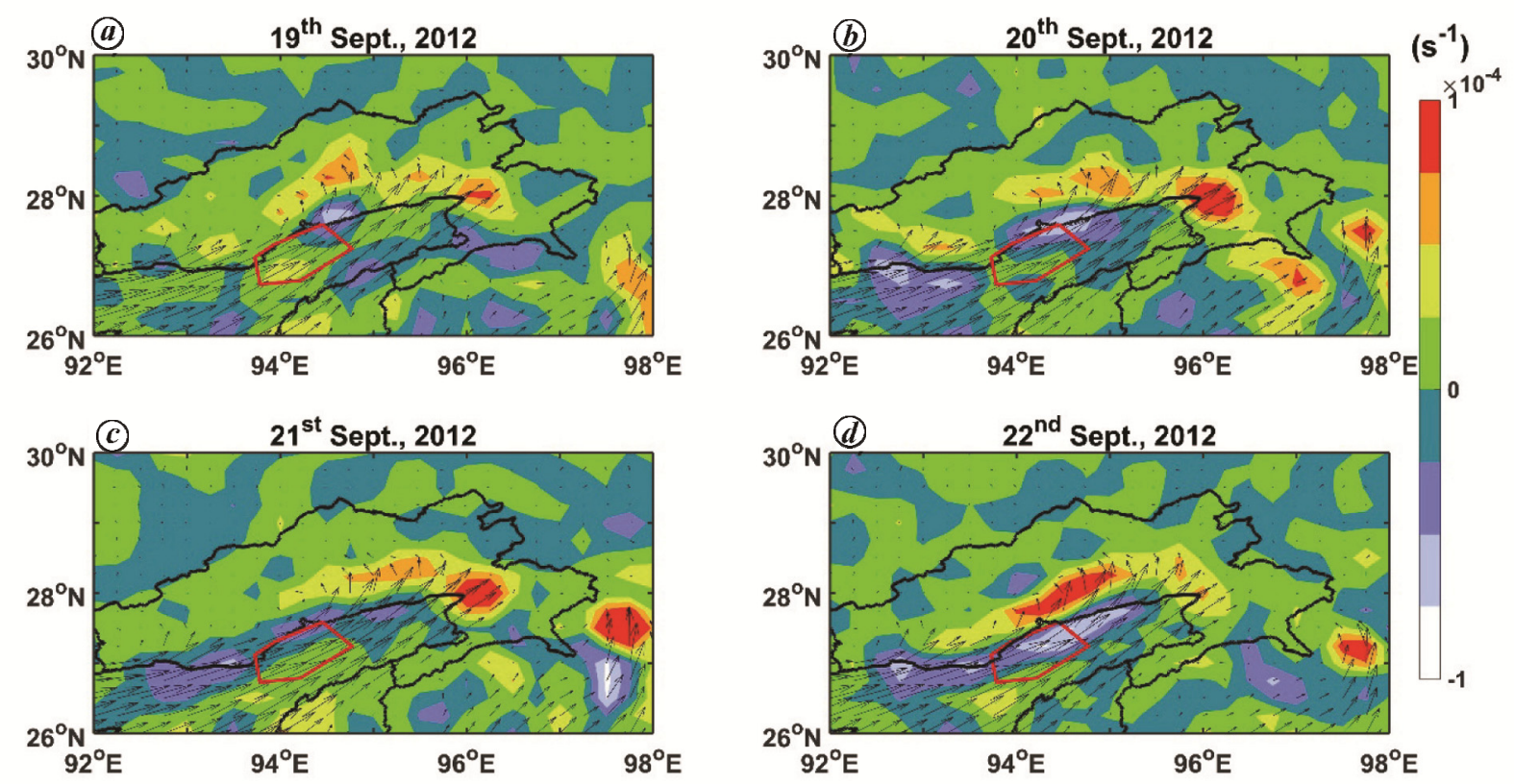

Figure 3. Convergence and wind direction at $850 \mathrm{hPa}$ over LSB and Arunachal Pradesh on (a) 19, (b) 20, (c) 21 and (d) 22 September 2012. Red box shows the study area (Lower Subansiri Basin) in the plains of Assam. Source: ERA5 $0.25^{\circ} \times 0.25^{\circ}$ Reanalysis Product.

structure leading to potential orographic lifting of air mass laden with moisture leading to heavy rainfall. However, to obtain a clear picture regarding the orographic uplift of air mass due to the complex terrain, we analysed the vertical velocity (omega).

\section{Orographic effect}

It is well known that orographic lifting plays a significant role in rainfall over mountainous terrain ${ }^{18-21}$. To establish this, we analysed ERA5 vertical velocity over Box 1 (Figure $1 a$ ) along $26^{\circ}-30^{\circ} \mathrm{N}$ (Figure $4 a-d$ ). It is observed that the vertical velocity (omega) is negative (i.e. upward motion) coinciding with the location where the topography (data source: NGDC, NOAA, $1 \mathrm{~km} \times 1 \mathrm{~km}$ ) changes from the plains to the hills at $\sim 28^{\circ} \mathrm{N}$ (Figure $4 e$ ). It is our contention that this lifting provided by orography also imparts the conditions favourable for heavy rainfall observed over this region (Figure 2). The higher vertical velocity, convergence and heavy rainfall all coincide spatially, pointing to the possibility of orographic rainfall. It may be mentioned that orographic rainfall is not a surprising aspect over this region. However, extreme precipitation occurred during the retreating phase of the monsoon. The wind direction (southwesterly), convergence, and orographic lifting are all typical of the monsoon period leading to the exceptionally high rainfall event. With an understanding of the meteorological factors that led to heavy rainfall, we explored the impact of upstream rainfall on the flood situation and hence quantification of flood inundation over LSB using highresolution LANDSAT imageries.

\section{Inundation and flood-induced changes to land type}

The LANDSAT imageries clearly show the extreme inundation caused by the September 2012 flood over LSB (Figure $5 \mathrm{~b}$ ). Due to the 16 days repetition cycle of the satellite and its inability to scan at night, factors like the exact time of flooding and lag time between rainfall and inundation could not be established. However, the LANDSAT imagery on 26 September 2012 clearly shows that most parts of LSB are inundated by flood waters (Figure $5 \mathrm{~b}$ ). Depending upon the spectral reflectance by which the classes are best represented, we have used several optimal band combinations to extract and categorize the LULC classes. Using MLC supervized algorithm, the retrieved LANDSAT level-1 data have been classified into four categories, namely: (i) water, (ii) dense forest, (iii) light vegetation/agriculture and (iv) barren/sand/ uncultivated.

Considering the preceding and succeeding years of the event, classified LULC data were quantified. It was found that during 2012 water bodies increased by $\sim 1900 \mathrm{~km}^{2}$ compared to 2010. It was also found that just after the flood event in October 2012, the area under the light vegetation/agriculture class decreased by $\sim 18 \%$ (with respect to 2010) and this decrease persisted with an area coverage of $\sim 12 \%$ in October 2013 . However, the most concerning fact that has been identified from the space is the significant increase of barren soil after the flood event. It was observed that barren soil had increased by $\sim 47 \%$ after the flood event (Figure $6 \mathrm{~b}$ ). This indicates massive sand-casting in the low-lying areas (which mainly include agricultural lands). After the post-flood 

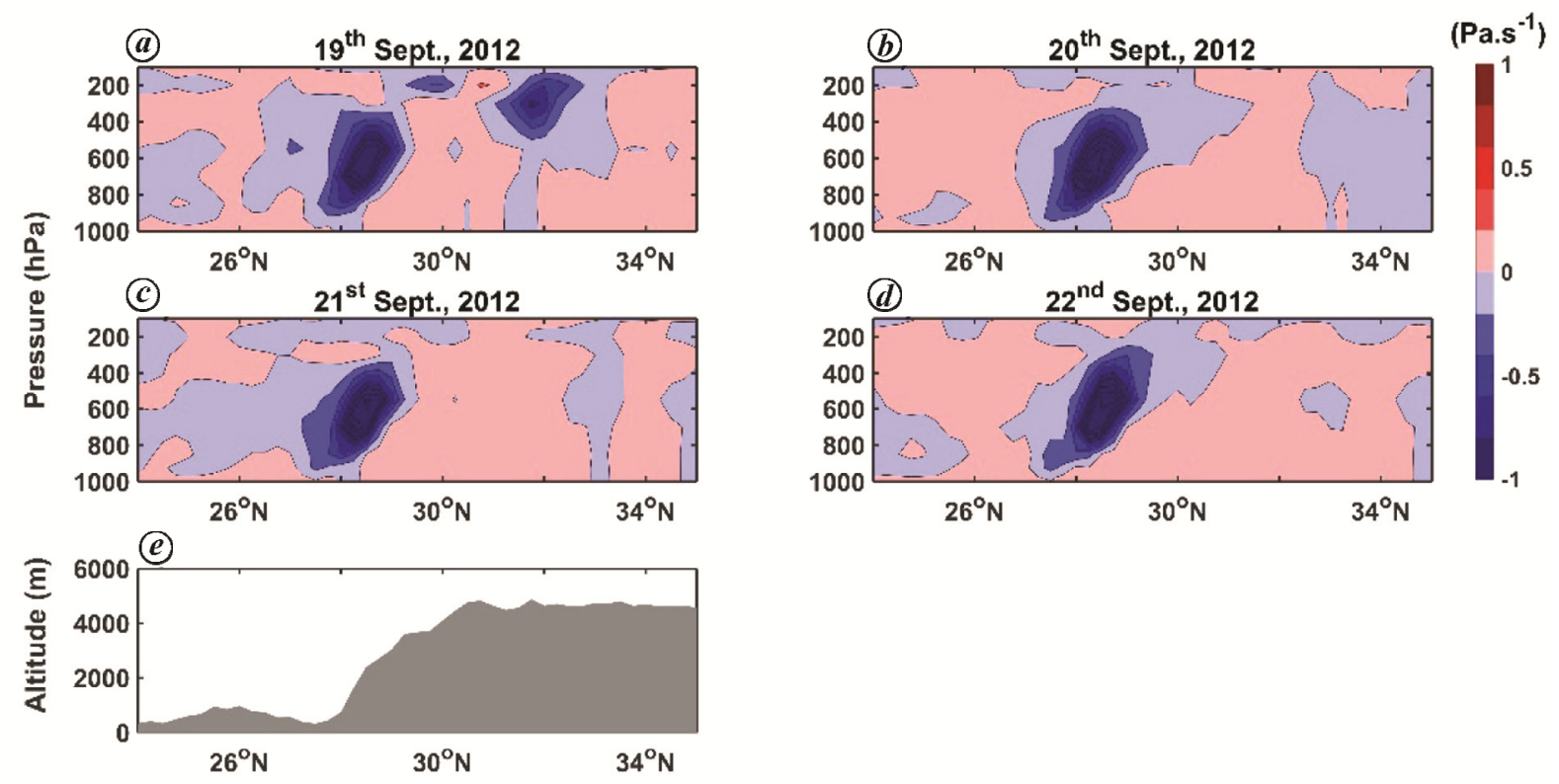

Figure 4. Longitude-averaged vertical velocity (omega) over LSB and Arunachal Pradesh on $(\boldsymbol{a}) 19,(\boldsymbol{b}) 20,(\boldsymbol{c}) 21$ and (d) 22 September 2012. $e$, Longitude-averaged topography along latitude. Source: ERA5 $0.25^{\circ} \times 0.25^{\circ}$. Topography data source: NGDC, NOAA $1 \mathrm{~km} \times 1 \mathrm{~km}$.
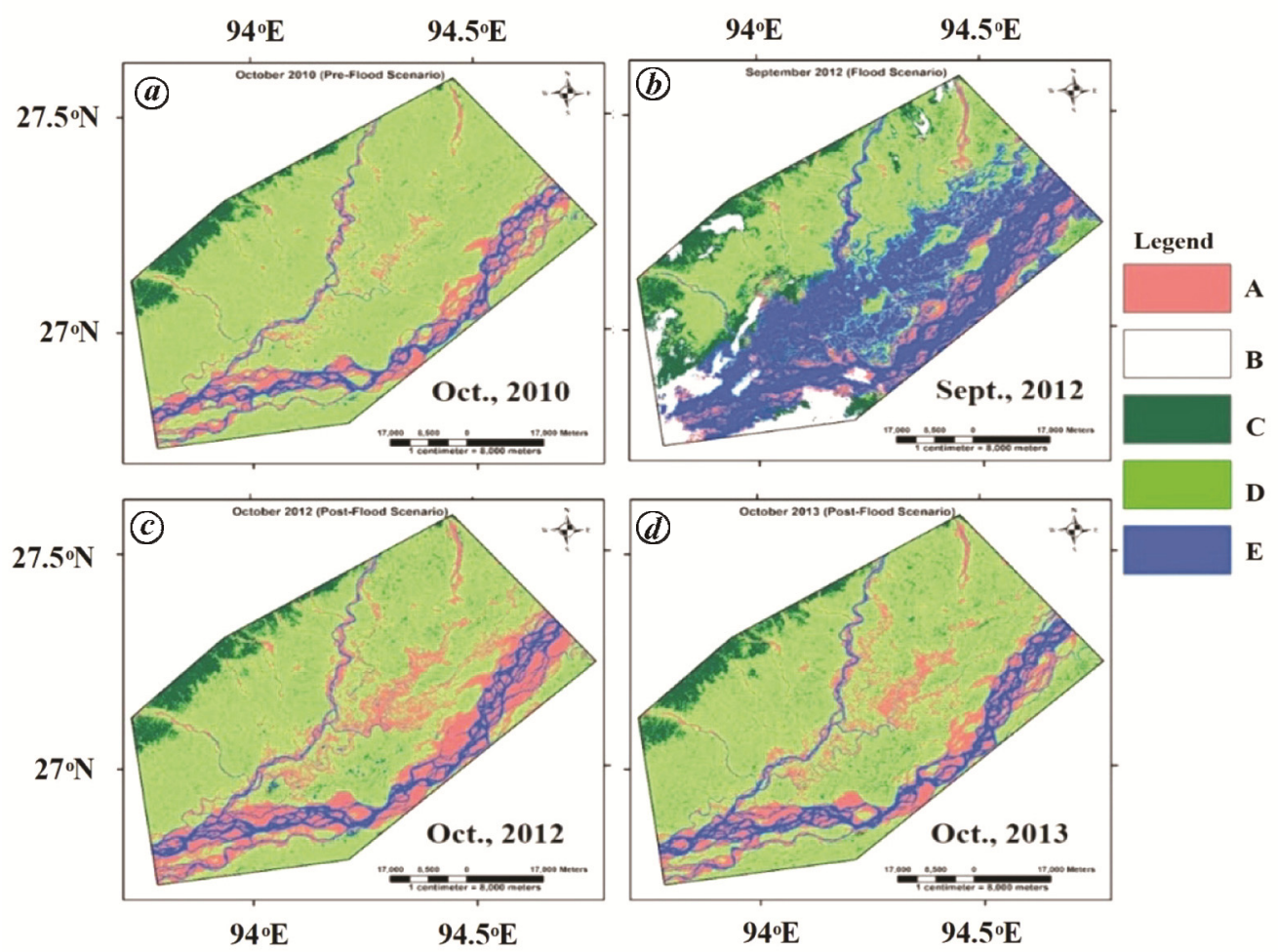

Figure 5. Land use and land cover (LULC) classification using maximum likelihood classifier (MLC) method over LSB of (a) 2010 (October), (b) 2012 (September), (c) 2012 (October) and (d) 2013 (October). Legend denotes LULC classes, (A) barren/ sand/uncultivated, (B) cloud, (C) dense forest, (D) light vegetation/agriculture and (E) water. Source: LANDSAT $(30 \mathrm{~m} \times 30 \mathrm{~m})$ dataset.

sand aggradation, which destroyed the agricultural fertility of the region, no further field visits were undertaken as to know how much time it took to regain its lost fertility. However, barren/sand class showed $\sim 21 \%$ increase in area (with respect to 2010) even in October 2013 (Figure $6 \mathrm{~b}$ ). This shows that recovery did not happen even a year after the floods. This may have significant impact on agricultural economy of the region. 

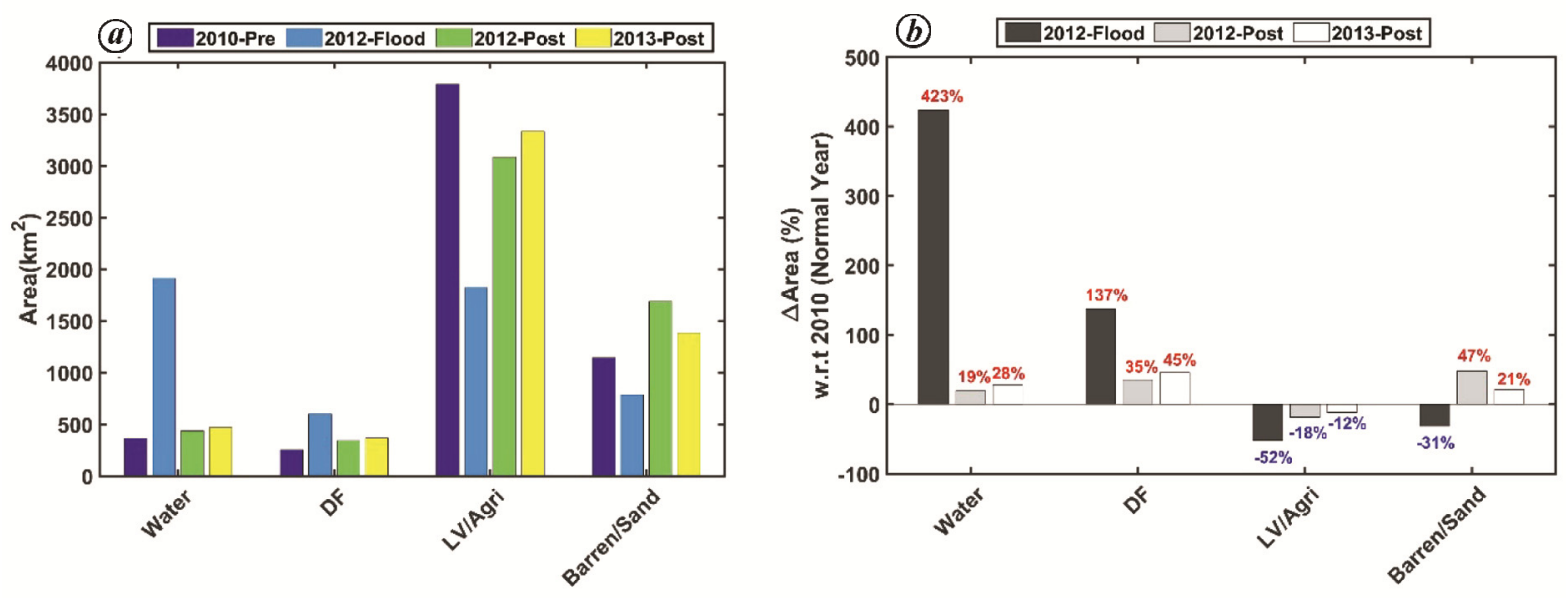

Figure 6. $\boldsymbol{a}$, Year wise LULC classification over LSB. $\boldsymbol{b}$, Change in LULC classes with respect to 2010 (normal year/pre-flood) in percentage. The classes classified using MLC supervised algorithm are: (i) water, (ii) dense forest (DF), (iii) light vegetation/agriculture (LV/Agri) and (iv) barren/sand/uncultivated (barren/sand). Source: LANDSAT $(30 \mathrm{~m} \times 30 \mathrm{~m})$ dataset.

Have the areas inundated by floods been converted to barren soil post-flood sand aggradation? To verify this, we have used field-survey evidences collected during 2012. It may be noted that the largest increase in barren land does not coincide with the inundation shown in Figure $5 \mathrm{~b}$. This may be possible due to the following reasons. Figure $5 b$ may not necessarily show all the areas inundated during the floods, since the imagery corresponds to 26 September 2012. It is possible that the floods may have receded from the low-lying areas by this time. It is also possible that due to errors in classification or due to the time lag in the data retrieval, there may be misrepresentation of the light vegetation class and this may be considered as one of the limitations.

It may be pointed out that, in the first phase of the flood during July 2012, water had exceeded the danger level and was approximately close to highest flood level in several places like Dibrugarh and Naharkatiya in Assam $^{14}$. Thus, the 2012 flood event is one of the most severe that occurred in the Brahmaputra basin. In addition, there are several studies that emphasize upon the vulnerability and frequency of flood over the Brahmaputra basin, where enhanced intensity of monsoon rainfall over the region, low gradient and flat terrain are designated as the prime factors causing floods $\mathrm{s}^{4,7,22}$.

\section{Field verification of floods and their impact}

It was observed that post-flood and aggradation is very high in the region. The source of these sediments is likely to be primarily from the Arunachal Himalaya. The friable bank materials of the rivers also yield a part of the total sediment load due to very high erosion rate (Figure $7 e)$.

Field surveys during October and December after the flood event of 2012 revealed thick layers of white sand without organic matter encrusting fertile agricultural lands and destroying their productivity (Figure $7 d$ and $f$ ). Studies carried out to assess the post-flood economic conditions of local people have highlighted the severity of sand deposition and its role in decreasing the fertility of agricultural lands ${ }^{23}$. The post-flood survey clearly shows that submerged regions are under a thick/thin layer of sand that largely impacts agricultural activities on the banks of the river. No studies have been conducted as yet on the time required to regain the lost soil fertility after such flood events.

Several studies have already assessed and quantified the impact of floods using different observational and remote sensing techniques ${ }^{13,14,24-27}$. However, studies that have linked meteorology, and flood and post-flood impacts are scanty over the Brahmaputra basin. Therefore, in this study we link causes of floods, their immediate impact on inundation and post-flood damage assessment downstream.

\section{Summary}

This study aims at establishing the significant role of meteorology in the severe flood of September 2012 in the north Brahmaputra plain. However, this necessitates developing a more robust and validated flood forecast model coupled with a reliable meteorological model for the Brahmaputra basin. Uneven topography which is seen to modulate and intensify the monsoon necessitates requirement for very high spatial resolution numerical model simulations with parameterization developed specifically for mountainous terrains. In addition, this study also proposes close coordination between the various disciplines such as those dealing with high-resolution regional climate modelling, remote sensing, hydrology, geology and policy-making for a better understanding of 
(a)
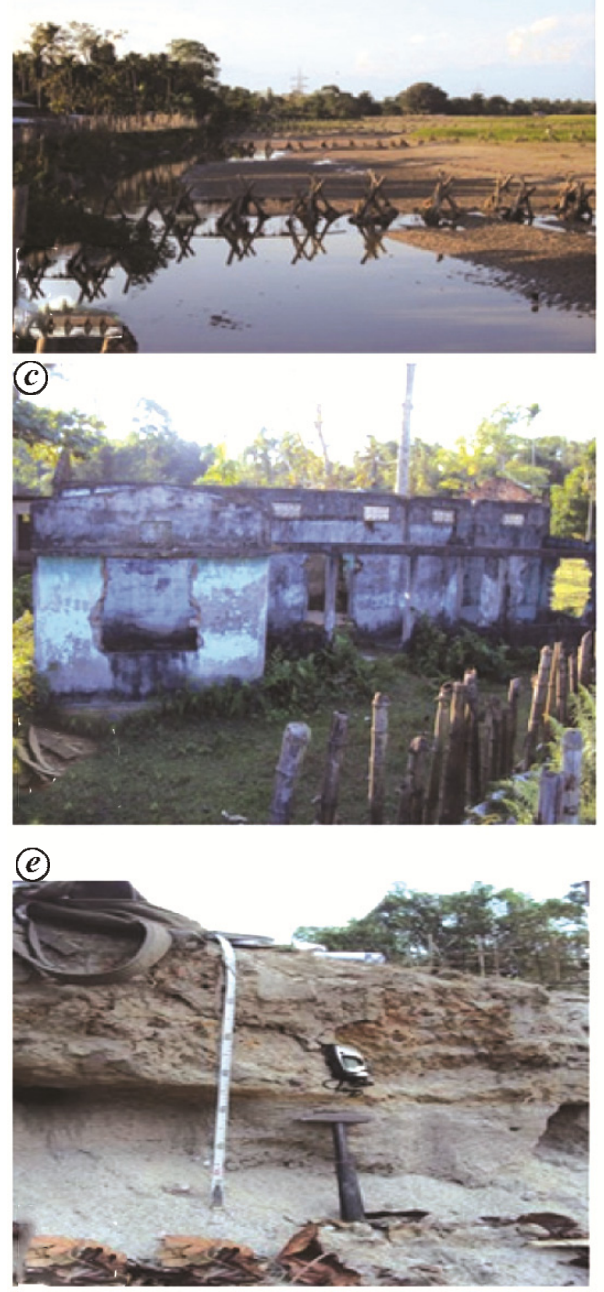

(b)
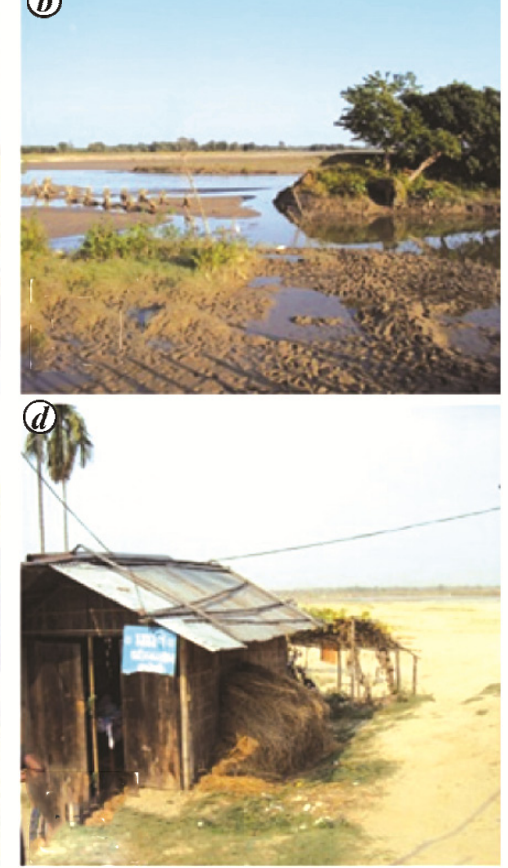

(f)

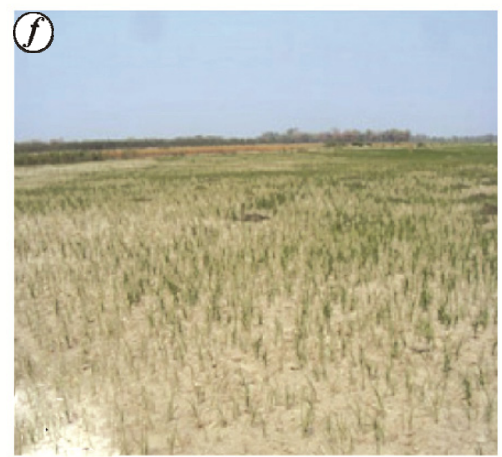

Figure 7. Flood damage in LSB. $\boldsymbol{a}, \boldsymbol{b}$, Extensive erosion (near Bihpuria). $\boldsymbol{c}$, Abandoned settlement following recurring floods and erosion. $\boldsymbol{d}$, A makeshift medical store in the midst of a sheet of sand left over by the floods during 2012 (near Maricha Pathar). $\boldsymbol{e}$, Section of a bank in LSB (near Mora Dikrang) showing loose sediments in the bank. $\boldsymbol{f}$, Failed cultivation after sand deposition/aggradation following the flood. Source: Ground field surveys done by the present authors during October 2012.

extreme rainfall events and the resulting floods, their mitigation and adaptation.

The major findings of the present study can be summarized as follows:

(i) Daily rainfall increased by $\sim 250 \mathrm{~mm}$ over LHR upstream of LSB during 19 to 22 September 2012.

(ii) Orographic effect played an important role in the intensification of rainfall during this period.

(iii) Severe floods occurred in LSB, further downstream of LHR, submerging an area of $>1900 \mathrm{~km}^{2}$, thereby increasing barren soil by $\sim 47 \%$ after the floods.

(iv) The floods also brought along massive amount of sand eroded from the loosely composed banks of fragile Neogene clastics.

(v) As the floods receded, productivity of agricultural lands decreased due to sand deposits during the floods, thereby disrupting the agrarian economy of the region for many cropping seasons.

1. WMO, Annual Report, World Meteorological Organization, Geneva, Switzerland, 1994.

2. WMO, Atlas of Mortality and Economic Losses from Weather, Climate and Water Extremes, WMO No. 1123, World Meteorological Organization, Geneva, Switzerland, 2014.

3. Das, R. K., Census of India 2011: Provisional Population Totals Assam, Series 19, Paper 1, 2011.

4. Dhar, O. N. and Nandargi, S., A study of floods in the Brahmaputra basin in India. Int. J. Climatol., 2000, 20, 771-781.

5. Goswami, B. N., Venugopal, V., Sengupta, D., Madhusoodanan, M. S. and Xavier, P. K., Increasing trend of extreme rain events over India in a warming environment. Science, 2006, 314, 14421444.

6. Varikoden, H. and Revadekar, J. V., On the extreme rainfall events during the southwest monsoon season in northeast regions of the Indian subcontinent. Meteorol. Appl., 2019, 1-13. 
7. Dhar, O. N. and Nandargi, S., Hydrometeorological aspects of floods in India. Nat. Hazards, 2003, 28, 1-33.

8. Shivaprasad Sharma, S. V., Parth Sarathi Roy, Chakravarthi, V., Srinivasarao, G. and Bhanumurthy, V., Extraction of detailed level flood hazard zones using multi-temporal historical satellite datasets - a case study of Kopili River Basin, Assam, India. Geomat. Nat. Hazards Risk, 2016, 8, 792-802.

9. De, U. S., Dube, R. K. and Rao, G. S. P., Extreme weather events over India in the last 100 years. J. Indian Geophys. Union, 2005, 9, 173-187.

10. Singh, Y., Ferrazzoli, P. and Rahmoune, R., Flood monitoring using microwave passive remote sensing (AMSR-E) in part of the Brahmaputra basin, India. Int. J. Remote Sensing, 2013, 34, 49674985.

11. Hazarika, N., Barman, D., Das, A. K., Sarma, A. K. and Borah, S. B., Assessing and mapping flood hazard, vulnerability and risk in the Upper Brahmaputra River valley using stakeholders' knowledge and multicriteria evaluation (MCE). J. Flood Risk Manage., 2018, 11, 700-716.

12. Jain, S. K., Saraf, A. K., Goswami, A. and Ahmad, T., Flood inundation mapping using NOAA AVHRR data. Water Resour. Manage., 2006, 20, 949-959.

13. Borah, S. B., Sivasankar, T., Ramya, M. N. S. and Raju, P. L. N., Flood inundation mapping and monitoring in Kaziranga National Park, Assam using Sentinel-1 SAR data. Environ. Monit. Assess., $2018,190,1-11$.

14. Bhatt, C. M. et al., Satellite images for extraction of flood disaster footprints and assessing the disaster impact: Brahmaputra floods of June-July 2012, Assam, India. Curr. Sci., 2013, 104, 1692 1700 .

15. Amante, C. and Eakins, B. W., Etopo1-1 arc-minute global relief model: procedures, data sources and analysis. NOAA Technical Memorandum, NESDIS NGDC-24 ETOPO1, 2009.

16. Kakade, S. B. and Dugam, S. S., Impact of cross-equatorial flow on intra-seasonal variability of Indian summer monsoon rainfall. Geophys. Res. Lett., 2008, 35, 1-5.

17. Vellore, R. K. et al., Monsoon-extratropical circulation interactions in Himalayan extreme rainfall. Climate Dyn., 2016, 46, 3517-3546.

18. Muhammad Tahir, K., Yin, Y., Wang, Y., Babar, Z. A. and Yan, D., Impact assessment of orography on the extreme precipitation event of July 2010 over Pakistan: a numerical study. $A d v$. Meteorol., 2015, 2015, 1-19.

19. Goswami, B. B., Mukhopadhyay, P., Mahanta, R. and Goswami, B. N., Multiscale interaction with topography and extreme rainfall events in the northeast Indian region. J. Geophys. Res.: Atmos. $2010,115,1-12$.
20. Prokop, P. and Walanus, A., Variation in the orographic extreme rain events over the Meghalaya Hills in northeast India in the two halves of the twentieth century. Theor. Appl. Climatol., 2015, 121, 389-399.

21. Houze Jr, R. A., Orographic effects on precipitating clouds. Rev. Geophys., 2012, 50, 1-47.

22. Yang, Y. C. E., Ray, P. A., Brown, C. M., Khalil, A. F. and Yu, W. H., Estimation of flood damage functions for river basin planning: a case study in Bangladesh. Nat. Hazards, 2014, 75, 2773-2791.

23. Das, K., Farm productivity loss due to flood-induced sand deposition: a study in Dhemaji, India, South Asian Netw. Dev. Environ. Econ., 2012.

24. Arvind, C. S., Vanjare, A., Omkar, S. N., Senthilnath, J., Mani, V. and Diwakar, P. G., Flood assessment using multi-temporal MODIS satellite images. Procedia - Comput. Sci., 2016, 89, 575586.

25. Jamir, T., Gadgil, A. and De, U. S., Recent floods related natural hazards over west coast and Northeast India. J. Indian Geophys. Union, 2008, 12, 179-182.

26. Goyari, P., Flood damages and sustainability of agriculture in Assam. Econ. Polit. Wkly, 2005, 40, 2723-2729.

27. Gaurav, K., Panda, R. and Sinha, P. K., The Indus flood of 2010 in Pakistan: a perspective analysis using remote sensing data. Nat. Hazards, 2011, 59, 1815-1826.

ACKNOWLEDGEMENTS. We thank the Government of India, Department of Science and Technology (DST-SPLICE, Climate Change Programme) for supporting part of this work through its grant DST/ $\mathrm{CCP} / \mathrm{NUC} / 148 / 2018(\mathrm{G})$. We also thank IIT Bhubaneswar for providing computational facilities; the Ministry of Human Resource Development (MHRD), Government of India for providing research fellowship to P.P.G. and Gauhati University for the necessary logistics and technical support while carrying out field surveys. We also thank ECMWF for ERA5 reanalysis products, National Geophysical Data Center (NGDC), NOAA for the elevation dataset, and NASA for the TRMM/LANDSAT data products used in this study; Pritom Sharma, Devraj Sonowal, Jyotish Dutta and Pabitra Gogoi for data acquisition and field surveys, and the reviewers for their constructive comments and suggestions that helped improve this manuscript.

Received 8 April 2019; revised accepted 6 November 2019

doi: $10.18520 / \mathrm{cs} / \mathrm{v} 118 / \mathrm{i} 5 / 778-785$ 